\title{
RESSIGNIFICANDO IDENTIDADES: um estudo antropológico sobre experiências migratórias dos estudantes africanos no Brasil
}

\author{
Dulce Maria Domingos Chale João Mungoi*
}

\begin{abstract}
Partindo do pressuposto de que alteridade é um fenômeno universal e de que todos os grupos constroem categorias para classificar a si e ao outro, no presente artigo faz-se uma reflexão sobre a experiência singular de imigração estudantil no Brasil, a partir de uma perspectiva relacional que busca analisar as percepções e as configurações identitárias desses estudantes na sua relação com a população local que os classifica como africanos. Os dados analisados neste trabalho permitem refletir sobre a presença dos universitários africanos no Brasil, em geral, e em Porto Alegre, em particular, a partir de uma tríplice identidade: identidade nacional, identidade continental e identidade racial.
\end{abstract}

Palavras-chave: Identidade africana; Identidade étnica; Imigração estudantil.

\section{Introdução}

Este trabalho é fruto de uma pesquisa desenvolvida de setembro de 2004 a novembro de 2005 com estudantes universitários matriculados Instituições de Ensino Superior (IES) públicas e privadas, localizadas na cidade e região metropolitana de Porto Alegre. Partindo do pressuposto de que alteridade é um fenômeno universal e de que todos os grupos constroem categoria a fim de classificar a si e ao outro, no presente artigo faz-se uma reflexão sobre a experiência singular de imigração estudantil no Brasil, a partir de uma perspectiva relacional que busca analisar as

\footnotetext{
* Doutora em Antropologia Social, Membro da Academia de Ciência de Moçambique / Pesquisadora Associada ao Núcleo de Antropologia e Cidadania (NACl) da Universidade Federal do Rio Grande do Sul. Porto Alegre/Brasil.
} 
percepções e configurações identitárias desses estudantes na sua relação com a população local que os classifica como africanos.

Considerando que a identidade é uma construção social e dinâmica e que atores sociais utilizam diferentes formas e estratégias de negociação para a construção e reconstrução de suas identidades sociais e étnico-raciais, a hipótese que se levanta neste trabalho é de que neste processo de deslocamento, os estudantes africanos enfrentam conflitos e dilemas identitários onde as suas múltiplas identidades (individuais, coletivas, continentais e étnico-raciais) são acionadas e ressignificadas permanentemente em função de diferentes contextos e esferas sociais que se interpenetram.

Tratando-se de um tema complexo que envolve a dimensão subjetiva da construção e reconstrução das identidades sociais dos sujeitos a pesquisa fundamentou-se no método etnográfico que consistiu na observação direta e participante através de realização de visitas sistemáticas a residências de alguns estudantes e participação em festas africanas e outros eventos organizados pelos estudantes e na realização de entrevistas abertas com treze estudantes provenientes de sete países africanos inseridos em convênios interinstitucionais vigentes nas IES e em programas de cooperação cultural e educacional bilateral firmados entre os governos brasileiro e de seus respectivos países operacionalizada através do Programa de Estudante-Convênio gerido pelo Ministério de Educação e Cultura do Brasil em coordenação com outras instituições.

Foram entrevistados ao todo treze estudantes africanos, dos quais, três angolanos, uma cabo-verdiana, dois guineenses, quatro moçambicanos, um sãotomense, um nigeriano e um senegalês, todos residentes na cidade de Porto Alegre. Dos treze entrevistados, seis são de sexo feminino e sete do sexo masculino e tinham idades compreendidas entre 20 aos 36 anos de idade. Apenas um dos treze entrevistados não se classificou como negro. ${ }^{1}$ A escolha de número de estudantes a entrevistar foi aleatória. Contudo, ao selecioná-los, procurou-se dar conta da heterogeneidade do grupo tomando em consideração o tipo de vínculo com a as Instituições de Ensino Superior (IES), nacionalidade, sexo, estado civil, idade, cor da pele e tempo de estada no Brasil. A maior parte dos entrevistados era solteira e frequentava cursos de graduação e o seu tempo de permanência no Brasil variava de 4 meses a 7 anos. A

\footnotetext{
${ }^{1}$ A autoclassificação racial dos entrevistados foi considerada como um dado relevante para se analisar as suas percepções em relação às relações raciais no Brasil.
} 
coleta de dados foi igualmente efetuada através de entrevistas formais e informais com estudantes universitários brasileiro com diferentes laços com os estudantes africanos, ou seja, amigos, colegas entre outros.

\section{Reconstruindo e fortalecendo identidades: usos e significados da identidade africana}

Ao desembarcarem no território brasileiro, os estudantes se identificam às autoridades brasileiras com base na sua identidade nacional, ou seja, exibem um passaporte que os identifica como angolanos, cabo-verdianos, guineenses, moçambicanos, são-tomenses, nigerianos, senegaleses, etc. Portanto, cada um deles é portador de uma nacionalidade, um distintivo background e o seu capital de cultura ${ }^{2}$, o que significa que estes estudantes estão longe de constituírem grupos unitários com características rígidas e imutáveis. Neste processo de contato com o novo ambiente sociocultural, os valores e os discursos identitários destes estudantes são reconstruídos cotidiamente em função das experiências vividas.

No processo de sua inserção no Brasil, em particular em Porto Alegre, os estudantes passam a ser tratados de forma reducionista e homogênea como "os africanos". As particularidades nacionais, culturais, linguísticas, étnicas, religiosas e outras são ignoradas e mesmo desconhecidas pela maioria dos brasileiros. Neste contexto, os estudantes deixam de construir os seus discursos identitários com base nos critérios de classificação mais usuais nos seus países de origem, isto é, não é como chope, changana, bacongo, ovibundo, yorubá ou fula ${ }^{3}$ que os estudantes se identificam no contexto de interação com a população de acolhimento. Assim, eles começam a manejar uma identidade continental atribuída, isto é, a identidade africana. Isto significa que na nova realidade social e frente a uma "nova" identidade, os estudantes africanos se reconstroem cotidianamente no jogo das relações sociais. O idioma étnico, "ser africano", torna-se uma nova referência que aprendem a manejar acionando alguns traços diacríticos e práticas que lhes permitem a sua identificação como africanos.

Ao se analisar a identidade africana no contexto das relações dos estudantes africanos em Porto Alegre constata-se que o termo

\footnotetext{
${ }^{2}$ BARTH, Fredrick. "Grupos étnicos e suas fronteiras".

${ }^{3}$ Grupos etnolinguísticos de origem bantu de alguns estudantes entrevistados provenientes de Angola, Moçambique, Nigéria e Senegal.
} 
"africano" é utilizado numa perspectiva relacional como um idioma que marca diferenças entre um nós "africanos" e eles "brasileiros" no jogo das relações sociais, o que leva a crer que, de certa forma, os estudantes, mesmo não organizados politicamente se percebem como uma coletividade cujas identidades são concebidas em torno da "africanidade". Que "africanidade"? Como os grupos denominados africanos concebem a africanidade? Em que contexto?

O filosofo ganês, Appiah ${ }^{4}$ ressalta que ser "africano" implica necessariamente considerar que africano pode ser uma identidade utilizável desde que se considere que todos pertencem a comunidades diferentes com trajetórias, costumes, línguas e hábitos culturais diferenciados e não como pertencentes a um único Estado. Para este autor, não existe uma identidade africana final, visto que a mesma está em processo de formação e envolve "um certo sentido e contexto". É uma identidade que é atribuída e reconhecida pelos africanos, mas que deve ser reconstruída continuamente de forma não substancializada de modo a evitar a reificação destes grupos.

Outro aspecto destacado por este autor é que esta identidade continental, isto é, a identidade africana está se transformando em realidade cultural e institucional mediante organizações regionais e subregionais, onde todos compartilham um continente com seus problemas ecológicos, uma relação de dependência perante a economia mundial, o problema de racismo, visão do mundo industrializado etc. A identidade africana, neste contexto, representa para os africanos uma, entre muitas das suas identidades possíveis.

Cabe ressaltar que a questão da "raça" também está presente no discurso dos estudantes quando se trata de pensar a identidade africana. Através dos depoimentos dos entrevistados, foi possível notar que existem aqueles que consideram que a identidade africana não está associada à "raça", enquanto outros, a maioria, entendem que não se pode pensar na identidade africana sem pensar na "raça negra" como marca de identificação.

Lurdes, estudante guineense faz parte daqueles que dissociam a identidades africana da "raça" ao afirmar que:

${ }^{4}$ APPIAH, Kwame Anthony. Na casa do meu pai: a África na filosofia da cultura. 
Eu sou mais africano que uma negra. Eu vejo negra uma coisa assim pejorativa. (...). Eu me sinto africana, fala mais alto. (...).O que é ser negra?Porque a raça acho que existe só uma. Os brancos nunca se identificam como brancos. (...)

No que tange à identidade africana, os dados de campo revelam que assim como Appiah, os estudantes entrevistados acreditam na existência de uma identidade africana. Um dos aspectos a destacar é que eles se autodefinem como africanos e manejam esta categoria como um elemento de identificação no seu cotidiano em Porto Alegre. Quando se referem aos aspectos que os identificam africanos, alguns dão maior relevância aos aspectos subjetivos como o jeito de ser, pensar; outros, aos aspectos objetivos como a cor da pele, o traje, penteado, postura corporal; um outro grupo, finalmente, associa ambos elementos.

Neste processo da afirmação da africanidade, os elementos objetivos assumem uma importância simbólica. Percebeu-se, ao longo do trabalho de campo, que no seu dia-a-dia, os estudantes acionam alguns traços diacríticos como emblemas para marcar a diferença fora e dentro do grupo. O sotaque, a língua, o penteado, as festas "típicas", o traje, a dança, a música e comida são alguns dos traços manejados pelos estudantes no processo de reconstrução de suas identidades e definição de fronteiras. A fala de Mussá, estudante moçambicano é ilucidativo:

\section{(...). eu acredito sim que existe uma identidade africana sim (...). Só que esta identidade deve ser pensada em termos universais e particulares. Cada país é diferente do outro e mesmo dentro do país há diversidade (...). A nossa cor, o nosso traje, o nosso dialeto, a nossa comida, as nossas festas e a nossa forma de ser nos distingue dos negros brasileiros. Não pode ser a mesma coisas (...). A partir do momento que somos identificados como africanos significa que temos uma identidade e algo que nos diferencia dos outros.}

Nota-se, portanto, uma preocupação comum por parte destes estudantes em exaltar elementos considerados africanos. Os traços diacríticos manejados com mais frequência pelos estudantes são o penteado, o traje e o sotaque. A comida é mais ressaltada em eventos comemorativos. As festas africanas como são designadas por muitos brasileiros e africanos, constituem uma das formas mais importantes de sociabilidade dos estudantes africanos em Porto Alegre. É nestas festas que ocorre a convergência dos diferentes sub-grupos e grupos dos 
estudantes africanos e a sua interação com a população local. A festa, neste sentido, se torna um cenário intermediário para a articulação dos diferentes grupos e assume uma função pedagógica. Geralmente, as festas são realizadas anualmente com vista à comemoração das datas de independência nacional dos países africanos. Entretanto, existem ocasiões em que as festas são realizadas com outras finalidades (recepção de calouros, confraternização etc).

Constata-se assim que é sobretudo com base nestes elementos acima mencionados que os estudantes se identificam e são identificados como africanos. Uns são distinguidos porque falam português com um sotaque diferente, outros porque falam a língua materna quando estão em grupo e outros porque cortam e trançam seus cabelos de diferentes maneiras. Entretanto, estas manifestações variam de grupo para grupo e de indivíduo para indivíduo, ou seja, existem estudantes que procuram evidenciar a sua identidade e outros não. Os cabo-verdianos, por exemplo, quando estão em grupo preferem se expressar em crioulo, fato que é interpretado por alguns entrevistados como falta de consideração pelos que se encontram presentes, visto que eles estão cientes de que nem todo mundo compreende o crioulo. Alguns informantes mais críticos consideram que os cabo-verdianos têm uma atitude etnocêntrica em relação aos outros africanos por não se considerarem africanos e serem majoritariamente mestiços.

No debate que se lançou no presente trabalho sobre a identidade africana, um aspecto precisa ser destacado. Apesar de aos olhos de boa parte da população todos os estudantes originários do continente africano serem considerados africanos, no processo de interação intragrupal, o discurso mais enfatizado é o da identidade nacional, ou seja, os estudantes se identificam em função de suas nacionalidades. Poutignat e Streiff-Fenart ${ }^{5}$ destacam que numa pesquisa que realizaram na França nos anos noventa, também constataram que os estudantes da África negra circulam entre duas esferas de interação específicas. Uma esfera pública, que consiste na interação com os membros da sociedade local (o ônibus, a bilheteria, a rua, a loja) e universitária (a biblioteca, o restaurante universitário, a sala de aula) e outra esfera privada, onde se desenvolvem atividades de rede que sustentam a identidade in-group. É nesta esfera onde circulam bens e valores como a alimentação, a música, a dança

\footnotetext{
${ }^{5}$ POUTIGNAT, Philippe; STREIFF-FENART, Jocelyne. Teorias de etnicidade seguido de Grupos Étnicos e suas Fronteiras de Fredrick Barth.
} 
que são consumidos e negociados dentro desta esfera e representam simultaneamente potentes recursos de identificação como africanos e meios para se comunicar diferenças significativas entre os africanos. É assim que, no contexto de Porto Alegre, são realizadas festas da comunidade angolana, moçambicana, guineneense, cabo-verdiana etc.

Apesar das diferenciações internas vigentes entre os africanos, por vezes, marcadas por visões estereotipadas, o que se verifica é que na interação com os brasileiros, muitos fazem questão de se identificarem como africanos para serem mais facilmente perceptíveis e marcarem diferenças. Neste contexto, a etnicidade é vista como uma linguagem na medida que permite a comunicação entre os grupos. Muitos acreditam que a condição de africano lhes fornece um status diferenciado e menos desconfiança comparativamente aos negros brasileiros, como aponta João, estudante guineense na sua fala:

Ontem eu fui numa locadora aqui perto e o cara não queria fazer cadastro para eu alugar fitas porque pensou que eu era afrobrasileiro. A minha namorada disse que eu era estrangeiro. Eu disse que sou da Guine-Bissau. Ai ele mudou o tratamento. Isso aconteceu em muitos lugares, no shopping e ai eles dizem:tu não é daqui? Eu sempre faço questão de dizer que sou da Guiné (...). Sinto que há uma mudança de tratamento quando você diz que é africano.

A mesma situação foi identificada por Guy Massart num estudo realizado com estudantes caboverdianos no Rio de Janeiro, no qual mostra que estes falam com sotaque quando sujeitos a desconfiança por policiais na universidade, shoppings para mostrar que são estrangeiros.

\section{A experiência de ser negro e o preconceito de marca}

No contexto do presente trabalho, a abordagem da temática racial se focaliza nos relatos dos estudantes que foram vítimas de discriminação racial e das suas percepções em relação às desigualdades sociais existentes entre populações negras e brancas no Brasil. De um modo geral, as falas dos estudantes africanos revelam um sentimento de surpresa e decepção no que tange à discriminação racial no Brasil. Muitos referiram nos seus pronunciamentos que a realidade que vieram encontrar em Porto Alegre não correspondia com a que esperavam encontrar, uma vez que acreditavam que no Brasil a "democracia racial", ou seja, a ideia da igualdade entre as raças era um fato. 
O sociólogo argentino Alejandro Frigerio $^{6}$ aponta que a discriminação e a estigmatização baseadas em características culturais, fenótipos ou a combinação dos dois são, geralmente, as respostas mais comuns perante a chegada dos imigrantes.

Cabe ressaltar que o fato destes estudantes se encontrarem numa região cuja população é majoritariamente branca pode contribuir para que os mesmos criem um sentimento de não-pertencimento, uma vez que a maioria destes estudantes se autoclassifica e é vista como negra no contexto Porto- Alegrense. ${ }^{7}$ Oliven $^{8}$, no seu artigo "A invisibilidade Social e Simbólica do negro no Rio Grande do Sul", argumenta que no Rio Grande do Sul, o segundo Estado "mais claro" do Brasil, o negro está sujeito a uma invisibilidade simbólica e social. No ano 2000, os dados do IBGE indicavam que o Rio de Grande do Sul era o segundo estado com maior número de população branca (86\%), sendo minoritária a presença de pretos $(5,2 \%)$, pardos $(7,8 \%)$ - no total, $13 \%$ de negros - e indígenas $(0,2 \%)$. Ao comparar a situação do negro no Rio Grande do Sul e noutros estados, o autor aponta que:

[...] ao passo que em outros estados do Brasil, como a Bahia, o negro comparece como um dos formadores da identidade, no Rio Grande do Sul sua imagem é relegada a um segundo plano. De fato, a historiografia gaúcha tradicional, apesar de reconhecer a existência generalizada do escravo no Estado, insistiu na sua pouca importância no processo de trabalho. ${ }^{9}$

Do mesmo modo, ao se referir à situação do negro no Brasil, o sociólogo e escritor brasileiro Clóvis Moura, que desenvolveu vários trabalhos que refletem a situação social, econômica e social do negro neste país, no seu livro "Sociologia do negro brasileiro", argumenta que:

O negro urbano brasileiro, sobretudo no Sudeste e Sul do Brasil, tem uma trajetória que bem demonstra os mecanismos de barreira étnica que foram estabelecidos historicamente contra ele na sociedade branca [...] Bloqueios estratégicos que começam no próprio do grupo

\footnotetext{
${ }^{6}$ FRIGÉRIO, Alejandro. “A alegria é somente brasileira: a exotização dos migrantes brasileiros em Buenos Aires".

${ }^{7}$ Embora quase todos estudantes entrevistados tenham se classificado como negros (com exceção de um que se classificou como pardo), a tonalidade da sua cor de pele é variável. Existem estudantes com pigmentação mais clara e outros mais escura.

${ }^{8}$ OLIVEN, Ruben George Oliven. "A invisibilidade social e simbólica do negro no Rio Grande do Sul".

${ }^{9}$ Ibidem, p. 26.
} 
de família, passam pela educação primária, a escola de grau médio até a universidade, passam pela restrição no mercado de trabalho, na seleção de empregos, no nível de salários em cada profissão, na discriminação velada (ou manifesta) em certos espaços profissionais; [...] e também pelas restrições múltiplas durante todos os dias, meses e anos que representam a vida de um negro. ${ }^{10}$

Para uma melhor problematização da discriminação racial a que os estudantes africanos estão sujeitos em Porto Alegre, uma referência a alguns estudos realizados sobre o processo de integração de estudantes africanos em outros contextos no Brasil se revela pertinente. Inclui-se neste grupo estudos feitos por Maurício ${ }^{11}$ e Kaly ${ }^{12}$, autores que fizeram sua análise a partir de suas próprias experiências como negros e estudantes africanos no Brasil. Ambos referem que os estudantes universitários africanos enfrentam cotidianamente a discriminação racial devido à tonalidade da cor da pele.

Na sua pesquisa, Maurício, tomando como base os dados dos trabalhos etnográficos realizados em alguns ônibus do Rio de Janeiro e os relatos de estudantes angolanos e moçambicanos frequentadores deste meio de transporte, constata que:

[...] para meus informantes moçambicanos e angolanos, o preconceito racial no ônibus se expressa precisamente através de atitudes sutis, como quando as pessoas evitam sentar ao lado deles; quando querem sentar com determinadas categorias de pessoas e destratados ou tratados com desdém ou indiferença, fato que os faz pensar uma, duas vezes antes de sentar com alguém e passar por uma humilhação [...]. ${ }^{13}$

Na mesma perspectiva, Kaly destacou com base na sua própria experiência e de outros estudantes africanos residentes em Salvador e em outros estados brasileiros, que os estudantes africanos de "raça" branca (árabes e sul-africanos) não sofrem discriminação racial pelo fato de serem confundidos com brancos brasileiros, o que revela que a discriminação racial está ligada à cor da pele dos indivíduos e não às suas condições socioeconômicas. Kaly aponta que:

\footnotetext{
${ }^{10}$ MOURA, Clóvis. Sociologia do negro brasileiro, p. 8.

${ }^{11}$ MAURÍCIO, Adriano. Medo de assalto: a democracia racial em questão no ônibus público na cidade do Rio de Janeiro.

${ }^{12}$ KALY, Alain Pascal. Os estudantes africanos no Brasil e o preconceito racial. Documento apresentado no Seminário Migrações Internacionais: contribuições para Políticas.

${ }^{13}$ MAURÍCIO, op. cit., p. 96.
} 
[...] os estudantes africanos que conseguem morar bem, nos bairros "chiques", são inconscientemente obrigados a mostrar o tempo todo que tem condições para morar bem: vestir-se muito bem (calças sociais, sapatos sociais, camisas sociais [...]. Quando fica no playground para conversar ou fazer qualquer coisa, o visitante dirige-se a ele como se fosse porteiro. Para evitar sofrer estas constantes humilhações, muitos deles ficam sempre no apartamento quando estão em casa. ${ }^{14}$

As constatações apresentadas por estes dois autores também podem ser percebidas com os estudantes entrevistados e vai ao encontro com aquilo que Oracy Nogueira ${ }^{15}$ classifica de preconceito de marca. Num estudo comparativo entre as relações raciais no Brasil e nos Estados Unidos da América, este autor refere que no Brasil o preconceito racial é de marca pelo fato de ter como ponto de referência a aparência, os traços físicos, a fisionomia, os gestos e o sotaque do indivíduo. Na concepção de Nogueira, este preconceito se diferencia do preconceito racial de origem, praticado, sobretudo, nos Estados Unidos da América, cuja discriminação é feita em relação à descendência do indivíduo e não da sua cor de pele.

Os universitários africanos entrevistados destacam que foi a partir de experiências individuais e coletivas que tiveram no processo de interação social com amigos, vizinhos, colegas da faculdade, professores e com a sociedade em geral que começaram a redefinir a sua identidade em torno da "raça". A pesquisa apurou que no processo de interação com diferentes atores dentro e fora do meio universitário, os estudantes africanos se defrontam com situações que eles interpretam como discriminatórias, marcadas por esteriótipos e estigmas contra os negros em geral. A partir daí, passaram a perceber que a cor da sua pele lhes remetia a um lugar pouco prestigiado na sociedade brasileira. Trata-se de um lugar marcado pela exclusão social, discriminação racial, pelos estereótipos que não coincidem com a realidade social vivenciada pelos estudantes africanos nos seus países. Muitos estudantes ressaltaram que quando convivem em espaços frequentados majoritariamente por brancos, acabam tendo a sensação de que sua presença é questionada.

Para a maior parte dos estudantes a discriminação racial é mais visível quando estes transitam por lugares frequentados por pessoas com alto poder aquisitivo, como shoppings, supermercados ou lojas. Alguns

\footnotetext{
${ }^{14}$ KALY, op. cit., p. 473.

${ }^{15}$ NOGUEIRA, Oracy. Preconceito racial de Marca e preconceito racial de origem. Sugestão de um quadro de referência para a interpretação do material sobre relações raciais no Brasil.
} 
estudantes destacaram nas suas falas que a discriminação racial, mesmo não sendo explícita, ou seja, manifestada verbalmente, está implícita nas atitudes dos funcionários e das pessoas desses locais. Na maior parte dos relatos percebe-se que os estudantes são vistos com desconfiança, menosprezados ou simplesmente ignorados por causa da cor da sua pele. Identificaram-se igualmente casos de estudantes que já foram interpelados pela polícia por terem sido confundidos com bandidos ou traficantes.

Finalmente, no que tange às percepções dos estudantes às relações raciais no Brasil, um dos aspectos que tem despertado atenção diz respeito à invisibilidade dos negros em diferentes espaços da sociedade brasileira, em particular na universidade. Os estudantes africanos têm sido dos poucos negros presentes nas suas turmas, nos condomínios onde vivem, nos shoppings, nas praias e em outros lugares, contrastando assim, com a realidade dos seus países de origem onde a presença de pessoas negras é expressiva nestes espaços.

\section{Considerações finais}

Os dados analisados neste trabalho permitem refletir sobre a presença dos universitários africanos na área pesquisada, a partir de uma tríplice identidade: a identidade nacional, a identidade continental e a identidade racial. A condição de estrangeiro, africano e negro torna a permanência deste grupo em Porto Alegre marcada por conflitos, paradoxos e ambiguidades. Estas três categorias, isoladas ou associadas, assumem, simultaneamente, conotações positivas e negativas, em função do contexto em que são acionadas. É a partir destes e outros elementos que estes universitários se posicionam em diferentes esferas da sociedade brasileira, em particular, no meio universitário, e reconstroem cotidianamente suas práticas, discursos e vivências e consequentemente agem. Na qualidade de estrangeiros, este grupo enfrenta vários obstáculos que impedem a sua integração social em Porto Alegre.

Considera-se ainda que, estando inseridos numa sociedade onde os negros estão sujeitos ao preconceito devido à cor da sua pele, os estudantes africanos também estão propensos a serem discriminados racialmente, sobretudo, quando transitam por lugares pouco frequentados por este segmento étnico-racial, como shoppings, lojas, restaurantes, etc. São nestes momentos que a condição de africano, portanto, de negro estrangeiro, tem sido acionada por eles como um elemento diferenciador capaz de amenizar tal tratamento. Ao manejar tais categorias, estes 
sujeitos procuram marcar sua distinção perante os negros brasileiros, mostrando que são detentores de um background cultural e econômico diferenciado.

Os dados apresentados indicam igualmente que falar da identidade africana implica fazer referência a identidades complexas e contraditórias. Assim, o fato de todos estudantes serem provenientes do mesmo continente não deve ser visto como um elemento homegeneizador de suas identidades. A heterogeneidade destes estudantes se verifica em vários níveis, o que torna impossível traçar um perfil homogêneo dos mesmos. O aspecto comum entre eles é o fato de todos serem estudantes universitários, estrangeiros e vistos pela população que os acolheu como africanos. Esta atribuição confere um certo sentido à esta africanidade e assume um papel central na vida cotidiana destes universitários.

É importante frisar que no universo estudado, a identidade africana se baseia numa perspectiva relacional e contrastiva, ou seja, ela emerge no contexto da interação social entre os estudantes provenientes de diferentes países africanos e a população local e se revela como um idioma e mecanismo de comunicação. Nesta perspectiva, a necessidade de identificação como africanos surge como um meio de informar sobre um "nós" africano (não nacionais, outsiders) a um "eles" brasileiro (nacionais, estabelecidos). Assim, as marcas emblemáticas como insígnias, signos, vestimentas, assim como traços como os tipos de cabelo, penteados, festas, tornam-se relevantes para a construção de um discurso identitário destes sujeitos sociais. No processo da construção desta identidade entram em jogos múltiplos elementos que se constroem e reconstroem continuamente. Logo, tanto os aspectos objetivos como os subjetivos são fundamentais e complementares para a análise dos jogos das identidades destes sujeitos. Entretanto, apesar de evidente, a cor da pele raramente é acionada por estes estudantes como um elemento de construção identitária, o que os diferencia no processo de construção de etnicidade de grupos de negros brasileiros. Este é, a meu ver, um dos aspectos que torna peculiar o processo de construção da identidade étnica dos estudantes africanos em Porto Alegre.

É de destacar que as identidades nacionais são utilizadas, neste âmbito, como uma das principais formas de distinções internas e são mais realçadas nas festas africanas e através de redes e grupos de sociabilidade. Ao mesmo tempo, as festas africanas surgem como um espaço de convergência de vários grupos e sub-grupos de estudantes africanos e 
não-africanos. Ainda que as distinções baseadas na nacionalidade sejam reconhecidas e manejadas nas relações in group, a crença na existência de uma identidade africana está presente no discurso de todos estudantes. Mesmo possuindo trajetórias, histórias e proveniências diversas, o grupo pesquisado procura dar um sentido a esta identidade continental, a partir de contextos de interação específicos. Por isso, é muito comum os estudantes se apresentarem para os brasileiros, como africanos e procurarem ressaltar esta identidade através da recriação de um "mundo africano".

A principal ilação que se pode tirar deste debate é que neste jogo de relações, as identidades não podem ser vistas como um todo coerente, mas caracterizadas por ambiguidades, contradições, continuidades e descontinuidades. Considera-se também que, embora o Brasil fomente a concretização do principal projeto destes estudantes, que é de se formar, os mesmos são vítimas de duplo preconceito, o de marca e o de origem, tal como definido por Nogueira ${ }^{16}$. O preconceito de marca surge em decorrência de sua cor da pele e a de origem por serem provenientes de países africanos. Por serem africanos, estes estudantes são considerados como "estrangeiros de segunda categoria" e, portanto, em condições abaixo dos brasileiros, fato que cria decepções na maior parte destes estudantes que concebiam o Brasil como um "paraíso terrestre".

Para finalizar, deve-se elucidar que com a presença dos estudantes universitários em Porto Alegre, sobretudo no meio universitário, como espaço pedagógico, desconstrução de esteriótipos e de produção de conhecimento, novos saberes podem ser produzidos a partir da veiculação de novos valores culturais, favorecendo assim o fortalecimento de relações históricas entre o Brasil e o continente africano e a desconstrução de imagens simplistas da África e dos africanos. Neste contexto, a formulação e a implementação de políticas públicas no âmbito de cooperação educacional favoráveis ao incremento de estudantes convênios (africanos e não só) nas universidades brasileiras surge como uma oportunidade ímpar para o fortalecimento de laços, convivência e conhecimento mútuo de pessoas de origens e culturas diferentes.

\section{Bibliografia}

APPIAH, Kwame Anthony. Na casa do meu pai: A África na filosofia da cultura. Rio de Janeiro: Ed.Contraponto, 1997.

\footnotetext{
${ }^{16}$ NOGUEIRA, op. cit.
} 
BARTH, Fredrick. "Grupos étnicos e suas fronteiras", in POUTIGNAT, Philippe; STREIFF-FENART, Jocelyne (orgs.), op. cit.

FRIGÉRIO, Alejandro. "A alegria é somente brasileira: a exotização dos migrantes brasileiros em Buenos Aires", in FRIGERIO, Alejandro; RIBEIRO, Gustavo Lins (orgs.). Argentinos e brasileiros: encontros, imagens e estereótipos. Petrópolis: Vozes, 2002.

KALY, Alain Pascal. Os estudantes africanos no Brasil e o preconceito racial. Documento apresentado no Seminário Migrações Internacionais: contribuições para Políticas. Brasil: Comissão Nacional para o Desenvolvimento da População (CNDP), 2000.

OLIVEN, Ruben George Oliven. "A invisibilidade Social e Simbólica Do Negro No Rio Grande do Sul", in BOAVENTURA, Ilka (org.). Negros no Sul do Brasil: Invisibilidade e Terriotorialidade. Ilha de Santa Catarina (SC): Letras contemporâneas, 1996.

MASSART, Guy. "Viajantes profissionais e estrangeiros cabo-verdianos no Rio de Janeiro: experiências do 'outro'", in MAGGIE, Yvonne e REZENDE, Claudi Barcellos (orgs.). Raça como Retórica: a construção da diferença. Rio de Janeiro: Civilização brasileira, 2001.

MAURÍCIO, Adriano. Medo de assalto: a democracia racial em questão no ônibus público na cidade do Rio de Janeiro. 1998. Dissertação (Mestrado em Sociologia e Antropologia) - Programa de Pós-graduação em Sociologia e Antropologia, Instituto de Filosofia e Ciências Sociais, Universidade Federal do Rio de Janeiro. Rio de Janeiro: UFRJ, 1998.

MINISTÉRIO DA EDUCAÇÃO. Manual do Programa de Estudantes-Convênio de Graduação. PEC-G. Brasília: Secretaria de Educação Superior, 2000.

MINISTÉRIO DAS RELAÇÕES EXTERIORES. Manual do Programa de EstudantesConvênio de Pós-Graduação. CAPES, CNPq. Brasília: Divisão de Temas Educacionais, 2005.

MOURA, Clóvis. Sociologia do negro brasileiro. São Paulo: Ática, 1988.

MUNGOI, Dulce M. D. C. João. "O mito atlântico": Relatando experiências singulares de mobilidade de estudantes africanos em Porto Alegre no jogo de contrução e reconstrução de suas identidades étnicas. Dissertação de Mestrado em Antropologia Social. Porto Alegre: UFRGS, 2006. Disponível em: www.lume.ufrgs.br/handle/10183/8028.

NOGUEIRA, Oracy. Preconceito racial de Marca e preconceito racial de origem. Sugestão de um quadro de referência para a interpretação do material sobre relações raciais no Brasil. São Paulo, 1954.

POUTIGNAT, Philippe; STREIFF-FENART, Jocelyne. Teorias de etnicidade seguido de Grupos Étnicos e suas Fronteiras de Fredrick Barth. São Paulo: UNESP, 1998. 


\section{Abstract}

\section{Reframing identities: an anthropological study on migration experiences of African students in Brazil}

Assuming that otherness is a universal phenomenon and that all groups construct categories in order to classify themselves and the others, this article presents a reflection on the singular experience of student migration in Brazil from a relational perspective that seeks to analyze the perceptions and identity configurations of these students in their relationship with the local population, who classifies them as Africans. The data analyzed in this work allows for a reflection on the presence of African university students in Brazil, in general, and in the state of Porto Alegre, in particular, from a triple identity: national identity, continental identity, and racial identity.

Keywords: African identity; Ethnic identity; Student immigration.

Recebido para publicação em 28/02/2012.

Aceito para publicação em 03/04/2012.

Received for publication in February, 28 ${ }^{\text {th }}, 2012$.

Accepted for publication in April, 03 ${ }^{\text {th }}, 2012$. 